\title{
Materiais didáticos elaborados por professores de química na perspectiva CTS: uma análise das unidades produzidas e das reflexões dos autores
}

\author{
Chemistry teaching in a STS perspective: \\ advances and obstacles experienced by teachers \\ in the elaboration of their own instructional materials
}

Erivanildo Lopes da Silva $^{1}$. Maria Eunice Ribeiro Marcondes ${ }^{2}$

\begin{abstract}
Resumo: Este trabalho apresenta uma análise, com base na perspectiva Ciência, Tecnologia e Sociedade (CTS), dos materiais didáticos elaborados por professores de química. Para tanto, foi elaborado um instrumento que buscava investigar os materiais construídos de acordo com os referencias discutidos em meio a uma intervenção. A análise das unidades didáticas mostrou que um pequeno número de professores ampliou o entendimento de temáticas CTS e construiu materiais com esses elementos. Mostrou, também, que outros professores, embora manifestando entendimento, elaboraram materiais instrucionais com ideias que podem ser consideradas simplistas. Foram identificados alguns fatores que podem justificar impedimentos, por parte dos professores, na construção e possível implementação dos materiais instrucionais, como: questões ligadas às políticas públicas, dificuldade em romper com a sequência tradicional em que os conteúdos são apresentados na maioria dos livros didáticos, e, sobretudo, uma resistência a uma nova visão de ensino que exigiria mudar a prática docente.
\end{abstract}

Palavras-chave: Ensino de química. Formação continuada de professores. Ciência, Tecnologia e Sociedade. CTS. Material didático.

\begin{abstract}
This work presents an analysis of materials produced by chemistry teachers based on the STS approach. A tool was elaborated to analyze the structure of these instructional materials. Theoretical and practical guidance were given to the teachers' group. In the beginning of the meetings, most teachers characterized STS teaching as a simple exemplification of everyday life and few teachers understood STS as a scientific description of facts and processes aimed at teaching chemistry. However, the materials produced by some teachers revealed an improvement of the understanding of STS. In addition, other teachers who seemed to have a high level of understanding, produced materials with simplistic views of the STS approach. Some difficulties pointed out by the teachers in considering applying the instructional materials were related to public policies, difficulty in disrupting the traditional sequence presented in most of textbooks, and a resistance to change their own view of teaching.
\end{abstract}

Keywords: Chemistry teaching. Teacher's continued education. Science, Technology and Society. STS. Didactic materials.

\footnotetext{
${ }^{1}$ Universidade Federal de Sergipe (UFS), campus prof. Alberto Carvalho, Avenida Olímpio Grande, s/n, CEP 49500-000, Itabaiana, SE, Brasil. E-mail: <erivanildolopes@gmail.com>

${ }^{2}$ Instituto de Química, Universidade de São Paulo (USP), São Paulo, SP, Brasil.
} 


\section{Introdução}

A contextualização no ensino de ciências em uma perspectiva Ciência/Tecnologia/ Sociedade (CTS) vem sendo defendida, por educadores e pesquisadores, como um princípio norteador de uma educação voltada para a cidadania, que possibilita a aprendizagem significativa de conhecimentos científicos e tecnológicos relacionados à sociedade. Neste sentido, os Parâmetros Curriculares Nacionais do Ensino Médio (PCNEM) (BRASIL, 1999) enfatizam que conteúdos e temas devem favorecer a compreensão do mundo natural, social, político e econômico.

Nessa perspectiva, o ensino das ciências da natureza tem como objetivo que os alunos possam compreender as interações entre ciência, tecnologia e sociedade; desenvolver a capacidade de resolver problemas e tomar decisões relativas às questões com as quais se deparam como cidadãos, baseados, também, em conhecimentos científicos. Tem-se, claramente, um meio de contextualização do ensino de Ciências, uma vez que este busca promover uma problematização de conhecimentos elaborados que considera aspectos sociais, históricos, éticos como focos da discussão.

Entretanto, a contextualização no ensino é fonte de diferentes interpretações e abordagens. Vários são os entendimentos sobre contextualização no ensino de Ciências, desde a exploração de situações corriqueiras ligadas ao dia a dia das pessoas, a contextualização na perspectiva do movimento CTS e, mais recentemente, a tendência CTS numa aproximação com a pedagogia de Paulo Freire. No nosso entendimento, esta última pode trazer uma maior contribuição para o Ensino de Química.

Neste trabalho, parte de uma pesquisa mais ampla, apresenta-se uma análise a respeito dos pressupostos do ensino de Química em uma vertente CTS apontados por professores na elaboração de seus materiais instrucionais. Além dos entendimentos manifestados, investigaram-se, também, os avanços e impedimentos na aplicação prática desses materiais. Uma ação de formação continuada, pautada na elaboração de materiais didáticos próprios, foi desenvolvida junto a esses professores, de maneira a revelar alguns dados sobre as concepções e práticas do grupo e, ainda, como se apropriaram das ideias discutidas.

\section{Bases teóricas}

A discussão de questões sociais, ensino de conceitos e desenvolvimento de atitudes e valores faz parte das ideias do movimento CTS no campo da educação (ACEVEDO, 2001; AIKENHEAD, 1994; AULER, 2003; SANTOS, 2002).

Acevedo (2001) aponta, pelo menos, três formas de entendimento da temática CTS no contexto educacional, como: (a) incremento e compreensão dos conhecimentos científicos e tecnológicos, assim como suas relações e diferenças, com o propósito de atrair mais alunos para estudos relacionados à ciência e tecnologia; (b) uma forma de potencializar os valores próprios da ciência e da tecnologia para entender o que delas se pode aportar na sociedade, considerando, também, aspectos éticos necessários para uso mais responsável, e (c) uma abordagem que possibilita, aos estudantes, obterem maior compreensão dos impactos sociais da ciência e da tecnologia, permitindo, assim, a participação informada na sociedade civil. Segundo o autor, 
este último ponto de vista é o que apresenta maior interesse numa educação básica e democrática para todas as pessoas. Nesse enfoque, ao ensino de Ciências com enfoque CTS teria como função preparar os futuros cidadãos para participarem ativamente no processo democrático de tomada de decisões na sociedade (CEREZO, 1999). Para tal, objetiva-se que os alunos possam compreender as interações entre ciência, tecnologia e sociedade; desenvolver a capacidade de resolver problemas e tomar decisões relativas às questões com as quais se deparam como cidadãos (ACEVEDO, 2001).

Com relação aos temas abordados, propostas de contextualização no ensino englobam desde questões do cotidiano, de cunho mais individual do que social, até as questões sociais, mais globalizadas. Ainda, essas propostas variam em relação às finalidades apontadas para a contextualização, que se remetem a questões relativas ao papel da educação na sociedade, envolvendo desde a formação de indivíduos cultos até a formação de indivíduos críticos, questionadores, que discutem a construção de um projeto de sociedade, passando por instâncias intermediárias, como: saber ser crítico nesse modelo de sociedade, poder julgar com conhecimento as decisões sobre Ciência e Tecnologia, e até participar democraticamente dessas decisões (AULER, 2001; 2003; AULER; FENALTI; DALMOLIN, 2007).

Como proposta metodológica para implementar tais ideias, destaca-se o modelo sugerido por Aikenhead (1994). De acordo com esse modelo, a situação de estudo deve partir de questões sociais relacionadas a conhecimentos tecnológicos e científicos. Dessa forma, o conhecimento científico é definido em função do tema e da tecnologia. Depois de compreendidos os conhecimentos científicos, retorna-se à tecnologia. Ao final, retoma-se a questão social. Esse estudo sistemático, segundo o autor, permite a tomada de decisão sobre a questão social.

As orientações do movimento CTS, segundo pesquisadores como Auler $(2001,2003)$ e Santos (2002), apresentam similaridades com as da pedagogia de Paulo Freire. Entre as semelhanças, destaca-se o ensino baseado em temas geradores, partindo de estudo do meio social e político do aluno. Auler, Fenalti e Dalmolin (2007) ressaltam, entretanto, que os temas geradores da pedagogia freireana são extraídos da prática de vida social dos alunos para serem problematizados, e isso não é uma característica marcante na perspectiva de ensino CTS. Para os autores, os temas geradores segundo a perspectiva CTS de ensino, embora relacionados ao meio social do aluno, são apresentados, geralmente, pelo próprio professor.

\section{Planejamento da pesquisa e procedimentos}

Fizeram parte desta pesquisa 17 professores de Química do Ensino Médio, da região metropolitana de São Paulo, que participaram de encontros de formação continuada, em que se visava discutir o ensino de Química na perspectiva de contextualização social. Foram realizados seis encontros, que perfizeram um total de 48 horas. Optou-se por adotar o modelo metodológico dos momentos pedagógicos de Delizoicov e Angotti (1991).

Dessa maneira, o primeiro momento pedagógico, a problematização do tema, foi a discussão dos possíveis entendimentos atribuídos à contextualização no ensino de Ciências, sobretudo à temática CTS. O segundo momento pedagógico, a sistematização do conhecimento, se deu por meio de discussões sobre os conhecimentos teóricos. O terceiro momento pedagógico, a aplicação do conhecimento, aconteceu na construção dos materiais instrucionais dos professores. 
Nesta pesquisa, foram usadas atividades de natureza descritiva e análise documental, que tinham o propósito de obter, dos professores, suas impressões após as discussões e reflexões em grupo (ANDRÉ; LÜDKE, 1986; BOGDAN; BIKLEN, 1994). Adotou-se a análise de documentos (unidades didáticas), pois estes materiais podem expressar os entendimentos dos professores.

Para a construção das unidades, foi sugerido o modelo estrutural proposto para elaboração de unidade didática contextualizada (MARCONDES et al., 2007). De acordo com esse modelo em um material didático deve-se apresentar, inicialmente, uma situação-problema com vistas a compreendê-la estruturalmente com base em conhecimentos químicos pertinentes relacionados a aspectos sociais e tecnológicos. Isso realizado com êxito permite que a situação -problema possa ser interpretada com uma nova leitura mais integralizadora.

Assim, para a análise das unidades didáticas, foi elaborado um modelo a partir da sobreposição do modelo de Marcondes et al. (2007) ao de Aikenhead (1994), por possibilitar um detalhamento dos conhecimentos tratados nas unidades didáticas (Figura 1).

O instrumento conta com um detalhamento de análise das partes das unidades didáticas, apresentadas a seguir:

1. Situação-problema ou tema - identificado pelo título dado à unidade didática e atividade de abertura. Verificou-se a presença de um tema ou ocorrência de uma problematização;

2. Visão geral do problema ou tema - parte do instrumento que permite a análise das informações que explicitam o tema ou problema abordado, e as relações com aspectos das áreas CTS que a unidade possa trazer em sua estrutura;

3. Conhecimento específico da Química - procurou-se verificar se o conhecimento da química tratado na unidade do professor estabelece relação forte, média ou fraca com o tema ou problema;

4. Nova leitura do tema ou problema - analisou-se se a unidade didática retoma alguma discussão sobre o tema ou problema ou não, apresenta nova situação que amplia os entendimentos sobre o problema ou, ainda, apresenta nova situação provocativa com vistas a resolver o problema.

Figura 1. Instrumento elaborado para análise das unidades didáticas

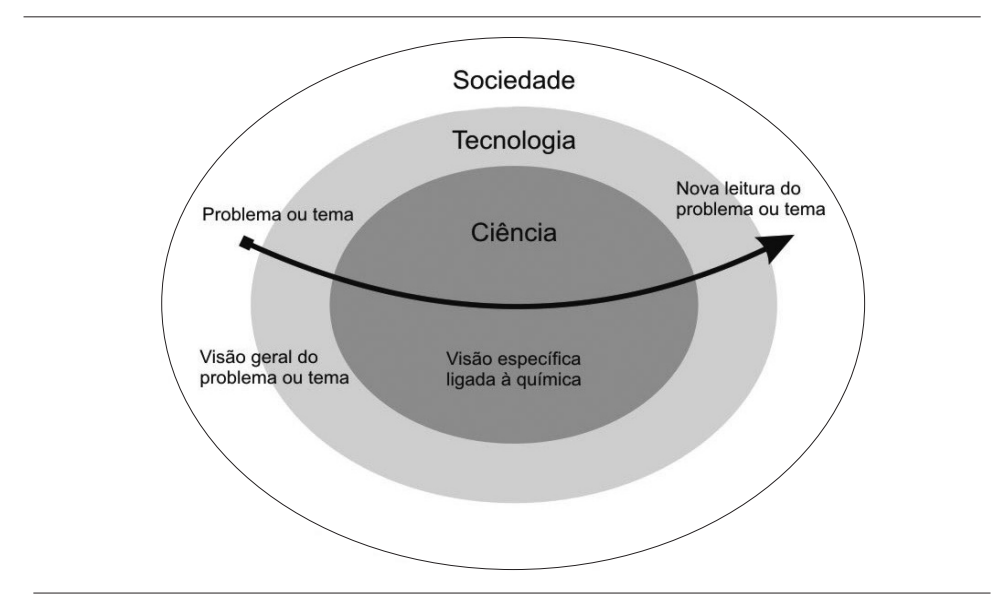

Fonte: Elaborado pelos autores. 
As unidades didáticas elaboradas pelos professores também foram analisadas por mais alguns critérios: os conhecimentos e focos das áreas CTS; a natureza das atividades propostas aos alunos, e as estratégias que os professores procuram utilizar para colocar as unidades didáticas em prática.

Após o término da intervenção, foram realizadas entrevistas com os professores que se prontificaram a colaborar com o pesquisador, o que resultou em seis educadores. Na entrevista, procurou-se verificar quais ideias os professores apresentavam sobre o ensino de Química contextualizado, e como e por que essas ideias se refletiram ou não em seus materiais instrucionais. Esses professores assinaram um termo de consentimento de uso dos dados na pesquisa.

\section{Discussão da vertente CTS nos materiais didáticos}

Logo no início dos encontros, foi realizada uma atividade que solicitava, aos professores, que fizessem escolhas entre duas possíveis abordagens de aulas contextualizadas no ensino de Ciências CTS: conceitual, direcionando a compreensão de contextos, ou contextual, encaminhando os desdobramentos conceituais (MORTIMER; MACHADO, 2007). A atividade também procurou investigar as estratégias empregadas pelos professores ao realizarem suas respectivas abordagens. Os dados encontram-se sistematizados na Tabela 1.

Tabela 1. Escolhas dos professores para realizar aulas contextualizadas CTS e suas estratégias

\begin{tabular}{|c|c|c|c|c|c|}
\hline & \multicolumn{2}{|c|}{$\begin{array}{c}\text { Foco para realizar aulas } \\
\text { contextualizadas }\end{array}$} & \multicolumn{3}{|c|}{ Estratégias para ensinar } \\
\hline & \multicolumn{2}{|c|}{$\begin{array}{c}\text { Conceitual: } \\
\text { direcionando o contextual }\end{array}$} & Exemplificação & Discussão & $\begin{array}{l}\text { Não } \\
\text { respondeu }\end{array}$ \\
\hline Professor & $\begin{array}{l}\text { P1, P2, P3, P4, P7, } \\
\text { P8, P9, P14 e P16 }\end{array}$ & $\begin{array}{l}\text { P5, P6, P10, P11, } \\
\text { P13, P15 e P } 17\end{array}$ & $\begin{array}{c}\text { P2, P3, P5, P6, P7, } \\
\text { P8, P9, P10, P11, } \\
\text { P14, P15 e P17 }\end{array}$ & $\begin{array}{l}\text { P1, P4, P13 } \\
\text { e P16 }\end{array}$ & P12 \\
\hline Total & 9 & 7 & 12 & 4 & 1 \\
\hline
\end{tabular}

Fonte: Elaborado pelos autores.

No que tange à contextualização, mais da metade dos professores (nove) apontou que, em suas aulas, optava pela abordagem conceitual. Assim, pode-se inferir que eles concebem os contextos como pretextos para ensinar química, o que Lutfi (1992) chama de "dourar a pílula".

Outros sete professores apontaram o estudo de contextos. Contudo, embora o número de professores tenha sido expressivo, apenas um apontou a estratégia de discussão como forma de abordagem contextualizada CTS. Acevedo (2001) pontua que o ensino CTS requer estratégias diferenciadas que superem o simples incremento ou exemplificação de aspectos contextuais. Assim, o que se pode afirmar é que somente o professor 13 apresentou um discurso alinhado com uma abordagem CTS do ensino de Ciências, pois foi o único a propor o foco no contexto direcionando o conceitual, com base na discussão como estratégia mais adequada para tal. 
Logo após discussões sobre contextualização CTS, os professores iniciaram o processo de construção de suas unidades didáticas. Ao final da intervenção, dos 17 professores que participaram, 15 as finalizaram, tendo sido produzido um total de nove unidades didáticas. Dessas, quatro foram construídas individualmente, quatro em duplas - proposta inicial do curso - e uma unidade construída em trio. Os temas abordados e os respectivos professores elaboradores estão apresentados no Quadro 1.

Quadro 1. Temas das unidades didáticas

\begin{tabular}{|c|l|c|}
\hline Unidade & \multicolumn{1}{|c|}{ Tema } & Professores \\
\hline 1 & Alimentos & P6 e P7 \\
\hline 2 & A Química do Solo & P8 \\
\hline 3 & Necessidade de Alimentos & P5 \\
\hline 4 & Compostos do Lixo & P14 \\
\hline 5 & Petróleo & P11 \\
\hline 6 & Produção de Lixo & P4 e P9 \\
\hline 7 & Lixo Doméstico & P2 P17 \\
\hline 8 & Elementos Químicos Presentes no Dia a Dia & P3 e P16 \\
\hline 9 & Pinturas rupestres no Brasil & P13 e P15 \\
\hline
\end{tabular}

Fonte: Elaborado pelos autores.

As unidades foram analisadas por meio do instrumento oriundo da simbiose dos modelos de Marcondes (2007) e Aikenhead (1994) (Vide metodologia).

A Figura 2 apresenta a estrutura da unidade didática 1, "Alimentos". Nela, os professores abordaram alguns conhecimentos de natureza social, tais como pirâmide alimentar e cardápio balanceado, porém não exploraram conhecimentos da área tecnológica. Com relação aos conhecimentos químicos, foram tratados conteúdos relativos a elementos químicos, como massa atômica e tabela periódica.

$\mathrm{Na}$ unidade didática em questão, não se percebeu a releitura da problemática a partir dos conhecimentos científicos apresentados, tampouco a introdução de conteúdos relativos à tecnologia. Assim, a unidade estruturada com essas características parece indicar que o objetivo dos professores estava mais focado no conceitual que no contextual (MORTIMER; MACHADO, 2007).

Na unidade didática "A Química do Solo” (Figura 3), percebe-se a intenção em abordar conteúdos relacionados à composição, fertilidade e nutrientes do solo como uma discussão socioambiental. Com relação a aspectos tecnológicos, é proposto um estudo de fertilizantes, agrotóxicos e transgênicos. $\mathrm{Na}$ análise do material didático em questão, percebe-se que os fertilizantes foram apresentados no âmbito das dimensões Tecnologia e Sociedade. Para a área da Ciência, a unidade se propôs a discutir conhecimentos de $\mathrm{pH}$, bases, ácidos e indicadores. 
Figura 2. Estrutura conceitual da unidade didática 1 "Alimentos"

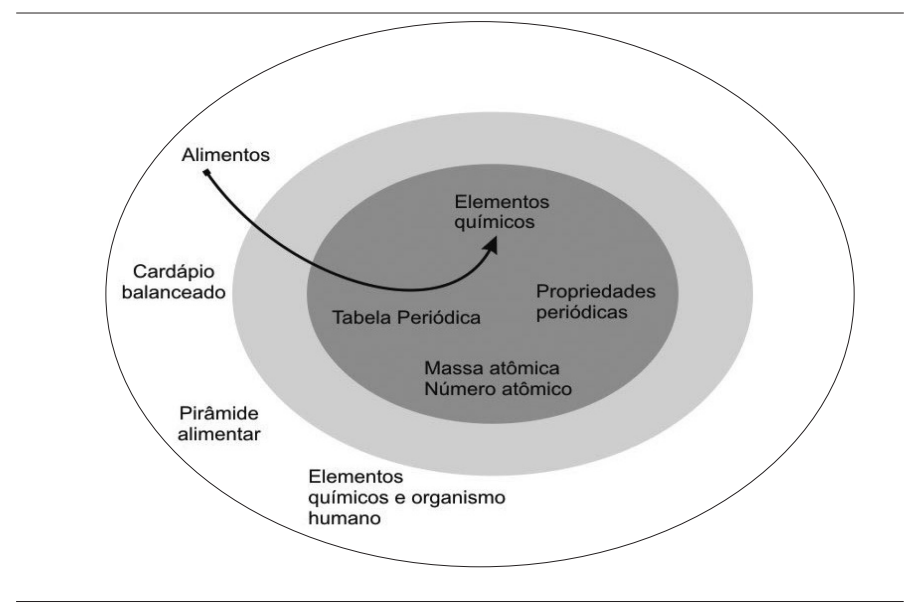

Fonte: Elaborado pelos autores.

Figura 3. Estrutura conceitual da unidade didática 2 "A química do solo"

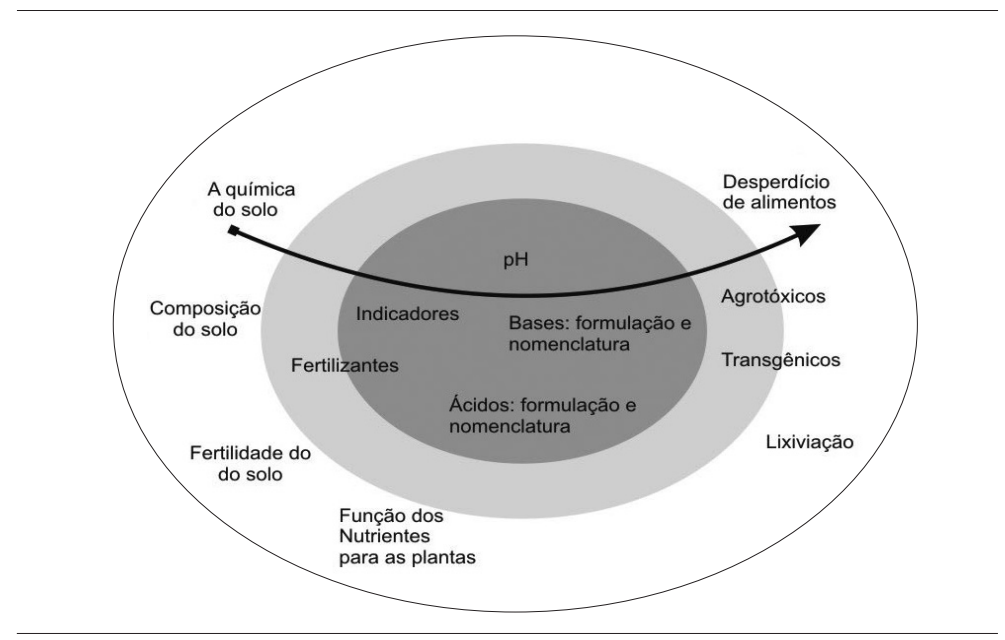

Fonte: Elaborado pelos autores.

Em uma perspectiva socioambiental, é proposto um estudo sobre a lixiviação do solo. Por fim, a unidade aborda o desperdício de alimentos em um contexto social. Essa análise revela que o professor realizou a construção de sua unidade considerando as questões das três áreas da dimensão CTS de forma bem integrada, pois percebe-se que determinados conteúdos são abordados em duas perspectivas das três dimensões.

A unidade didática 3 "Alimentos", cuja estrutura está representada na Figura 4, se inicia pela abordagem de questões relacionadas à energia dos alimentos e rotulagem nutricional. Apresenta conhecimentos sobre energia numa interface social e tecnológica. Destaca o item quantidade de calor como conhecimento técnico relacionado à Ciência. Entretanto, não 
Silva, E. L.; Marcondes, M. E. R.

é proposto o movimento de volta para a Sociedade, reinterpretando o problema ou propondo soluções, com base em conhecimentos tratados.

Verifica-se que a unidade didática não contemplou todas as etapas do modelo, pois foi atribuída maior relevância para os conteúdos: quantidade de calor, reações endotérmicas e exotérmicas, unidade de energia e entalpia.

A Figura 5 apresenta a estrutura da unidade didática 4, "Compostos do Lixo". Verifica-se que, ao construir a unidade, o professor explorou conhecimentos da área socioambiental e conteúdos químicos, porém não se ateve a nenhum conhecimento de natureza tecnológica.

Figura 4. Estrutura conceitual da unidade didática 3 "Necessidade de alimentos"

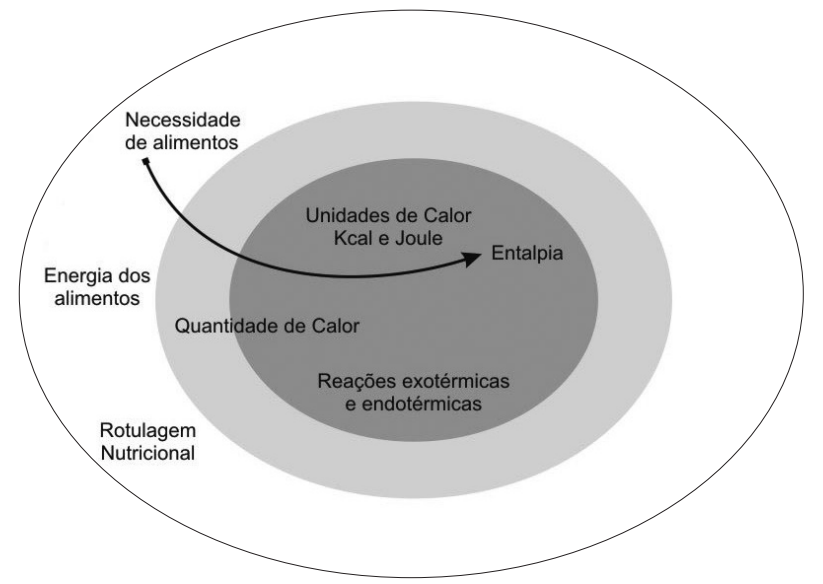

Fonte: Elaborado pelos autores.

Figura 5. Estrutura conceitual da unidade didática 4 "Compostos do lixo"

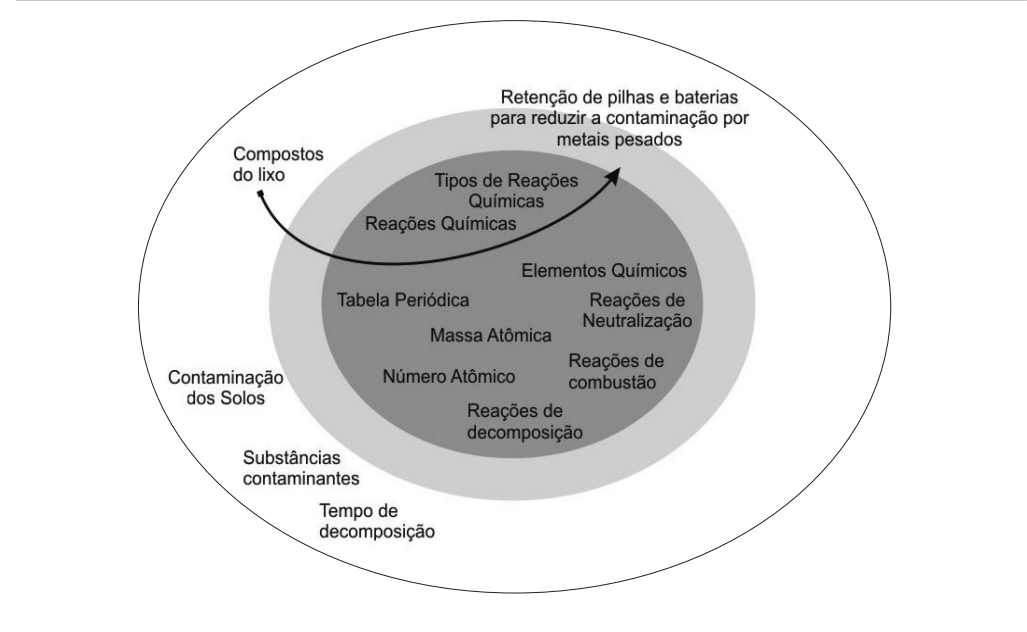

Fonte: Elaborado pelos autores. 
A unidade 4 apresenta grande quantidade de conhecimentos científicos, mas não foram estabelecidas relações explícitas entre alguns desses conteúdos e a situação-problema. Deve-se ressaltar, entretanto, que é proposta uma releitura do tema abordando o descarte de pilhas e baterias. A Figura 6 apresenta a estrutura da unidade didática 5, "Petróleo".

Figura 6. Estrutura conceitual da unidade didática 5 "Petróleo"

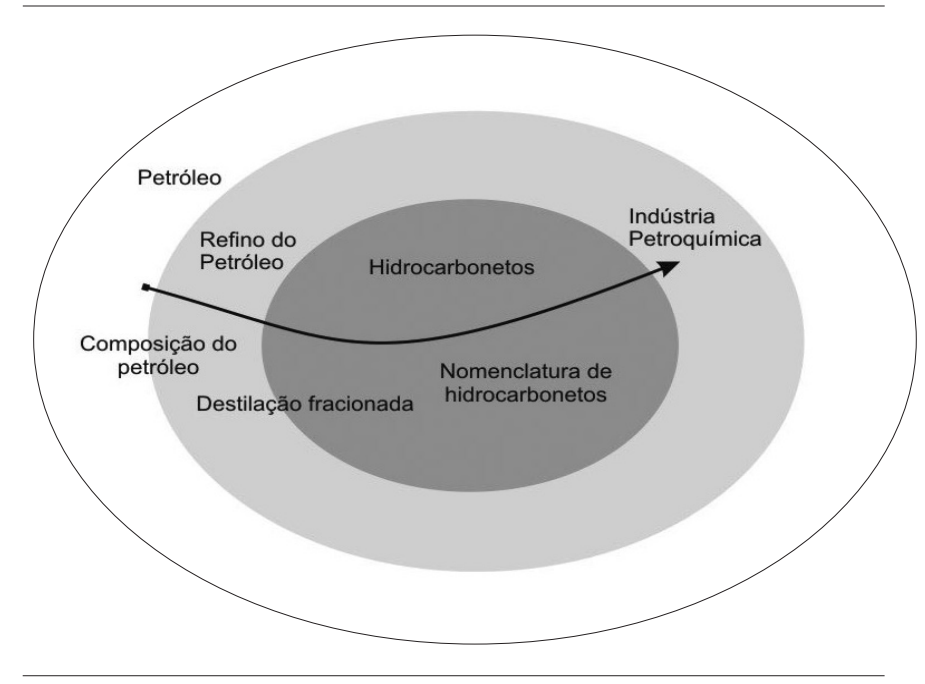

Fonte: Elaborado pelos autores.

A unidade apresenta o tema Petróleo, discute a composição do petróleo na interface Sociedade/Tecnologia e, ainda, com respeito à tecnologia, é apresentado o refino de petróleo. Vale ressaltar que a destilação fracionada é tratada antes dos conteúdos de hidrocarbonetos e sua nomenclatura. Chama a atenção, entretanto, a abordagem dada ao item indústria petroquímica, introduzido por meio de um texto em que prevalecem descrições de cunho tecnológico, sem que tenham sido tecidas quaisquer relações com aspectos sociais, nem mesmo é feita menção a algum impacto ambiental, tema recorrente quando se trata da indústria petroquímica.

Já a unidade 6 (Figura 7), "Produção de Lixo", se inicia por um texto que apresenta, numa perspectiva socioambiental, a contaminação do solo. Tal texto é complementado por outro que trata de alguns materiais contaminantes. O material aborda também, na interface Sociedade/Tecnologia, informações sobre a reciclagem de alguns materiais, como plásticos e metais do tipo alumínio. No que tange à Ciência, este parece ter sido o foco maior da unidade, uma vez que dá muita ênfase a conteúdos químicos. São tratados: elementos químicos, tabela periódica, massa atômica, número atômico, períodos e colunas (grupos).

A unidade 6, embora tenha explorado alguns aspectos da tecnologia nas interfaces Sociedade/Tecnologia, não apresentou conteúdos relativos a Ciência/Tecnologia. A sobreposição de informações no modelo de análise mostra forte apresentação de conteúdos de química que não se relacionam diretamente ao tema. Em outras palavras, o conceitual não visa explicar o contextual (MORTIMER; MACHADO, 2007). 
Silva, E. L.; Marcondes, M. E. R.

Figura 7. Estrutura conceitual da unidade didática 6 "Produção de lixo"

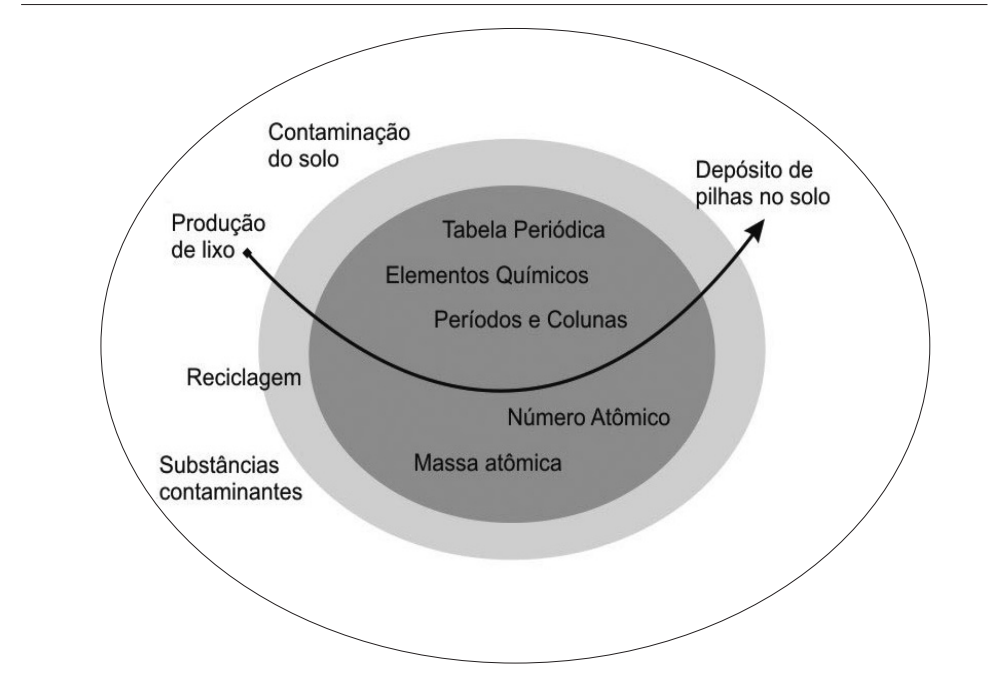

Fonte: Elaborado pelos autores.

A estrutura conceitual da unidade didática 7, "Lixo Doméstico", pode ser analisada a partir da Figura 8.

A unidade didática 7 apresenta conhecimentos em todas as áreas CTS, como sugere o modelo de sobreposição. No âmbito Sociedade/Tecnologia, a unidade apresenta os itens: desenvolvimento tecnológico, crescimento econômico, lixo doméstico, contaminação dos solos pela produção do lixo e aterros sanitários. Pode-se perceber um alto grau de coerência na seleção dos itens tratados, uma vez que tópicos como aterros sanitários, desenvolvimento tecnológico e processos químicos demarcam interfaces sociedade, tecnologia e ciência.

Figura 8. Estrutura conceitual da unidade didática 7 "Lixo doméstico"

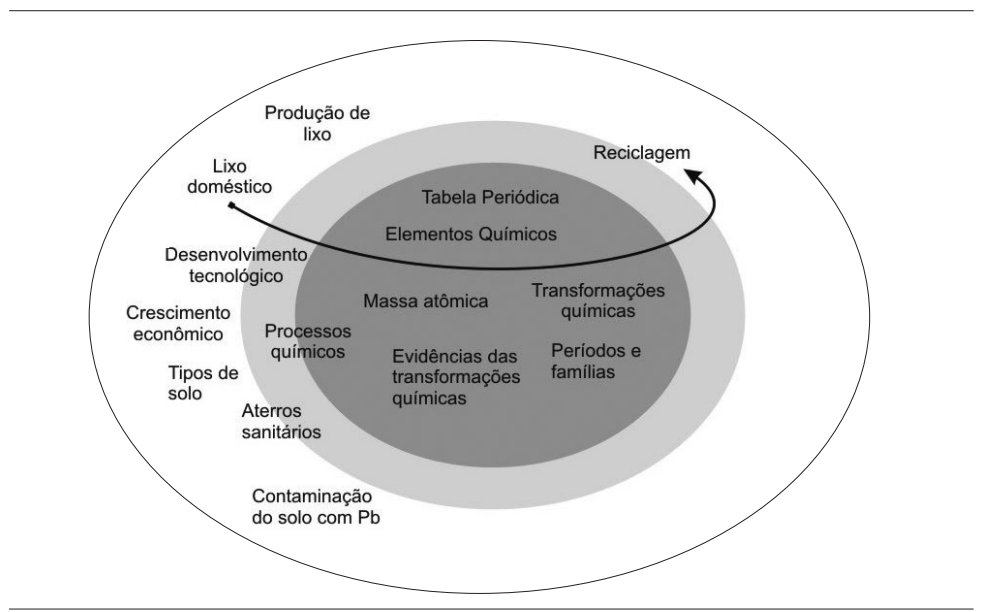

Fonte: Elaborado pelos autores. 
$\mathrm{Na}$ área da ciência, são apresentados os conteúdos: elementos químicos, tabela periódica, períodos e grupos, número atômico, massa atômica, transformações químicas e evidências das transformações químicas. Embora se possa concordar que parte desses conhecimentos realmente seja necessária para discutir o problema do lixo, como transformações químicas e elementos químicos, os demais não estabelecem a mesma relação. Isso evidencia certa tendência conteudista da unidade, contudo, dados os temas abordados, a unidade pode ser classificada na perspectiva do Contextual direcionando o Conceitual. Na unidade, o item Reciclagem foi abordado por meio de um texto que procurou articular Tecnologia e Sociedade, sendo essa a forma mais enfática em que a dimensão Tecnologia é explorada no material didático após a apresentação dos conteúdos da Ciência.

A unidade 8 (Figura 9), "Elementos químicos presentes no dia a dia”, se inicia por um tema sociocientífico, apresentando a questão de que elementos químicos estão presentes no dia a dia das pessoas. O item "obtenção na natureza” foi apresentado na interface entre Sociedade/ Tecnologia, e o item "processos de obtenção”, entre Tecnologia/Ciência. É importante enfatizar que esses conhecimentos, aparentemente, apresentaram-se em uma sequência proposital para ensinar Tabela Periódica, Propriedades Periódicas, ou seja, os professores tinham o foco no ensino de conteúdos de química.

Figura 9. Estrutura conceitual da unidade didática 8

"Elementos químicos presentes no dia a dia"

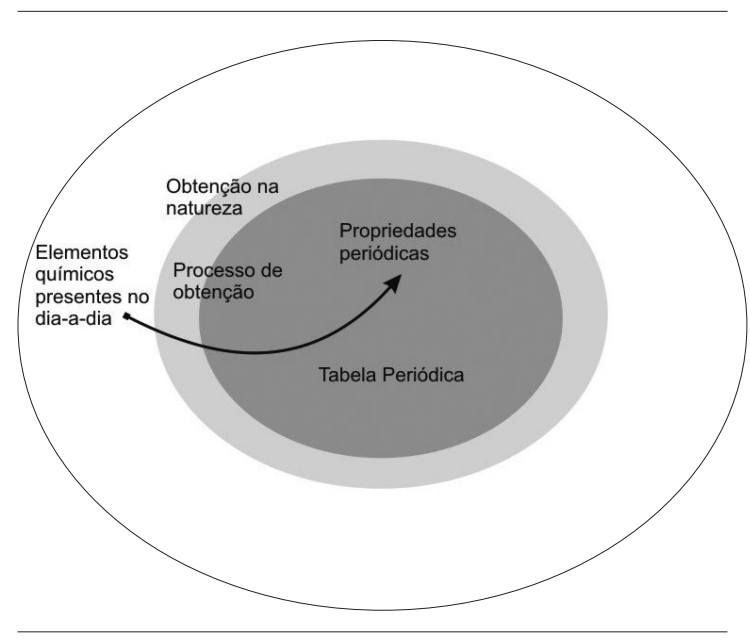

Fonte: Elaborado pelos autores.

Pode-se perceber que a unidade não se adéqua aos modelos propostos, uma vez que são poucas as relações estabelecidas entre a Ciência, Tecnologia e Sociedade. Como mostra a figura 9, não foi contemplada uma releitura da questão inicial, ou seja, não é proposto que os fatos ou situações apresentados sejam reinterpretados com base em conhecimentos da Ciência. Pode-se inferir que os professores não atingiram um nível de compreensão da contextualização 
que os permitisse elaborar uma unidade com maior integração dos conhecimentos; pode-se, também, concluir que esses professores não romperam as fronteiras de um modelo de ensino centrado no conteúdo específico, o que, certamente, é um obstáculo para a implementação de um modelo de perspectiva CTS.

A unidade didática 9, "Pinturas Rupestres no Brasil", elaborada por dois professores, está representada na Figura 10.

Figura 10. Estrutura conceitual da unidade didática 9

"Pinturas Rupestres no Brasil"

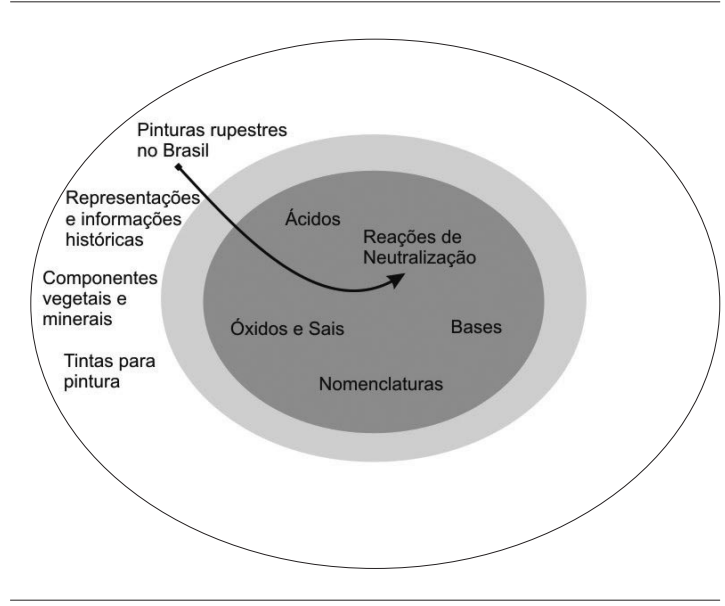

Fonte: Elaborado pelos autores.

A unidade se inicia por um tema de âmbito social - as questões das representações históricas das pinturas e os componentes das tintas -, avançando para conhecimentos químicos. A unidade tem pouca aproximação com o modelo de sobreposição, por não apresentar, sobretudo, nenhum conhecimento de Tecnologia e não propor a releitura da situação inicial.

Sintetizando, pode ser verificado que algumas das unidades apresentam alto grau de coerência e alguns descompassos, segundo os modelos sugeridos de construção de materiais instrucionais. As unidades 2, 4, 5, 6 e 7 apresentam estruturas que se aproximam dos modelos propostos, enquanto 1, 3, 8 e 9, embora apresentem alguns elementos desses modelos, parecem refletir um nível de contextualização menos elaborado. Não se trata de reduzir a questão a seguir ou não um modelo - pois os professores poderiam ter criado seus próprios caminhos -, mas, sim, de considerar as aproximações com as ideias de contextualização do conhecimento tendo em vista visões mais complexas, superando a exemplificação com fatos do cotidiano dos conteúdos científicos a serem ensinados, ou a simples descrição científica de processos químicos industriais ou ambientais.

O Quadro 2 sistematiza as informações sobre os conhecimentos relativos à Ciência, à Tecnologia e à Sociedade abordados nas unidades, segundo o modelo de Aikenhead (1994). Apresentamos, também, nossa interpretação, a partir da leitura das unidades, sobre o enfoque 
que prevalece na unidade, seja ele na Ciência (C), na Tecnologia (T), na Sociedade (S) ou CTS. As outras possibilidades, como CT, SC, SC, TC, TS e ST, não foram verificadas nas análises.

Com base no Quadro 2, pode-se perceber que as unidades 1 (Alimentos) e 9 (Pinturas Rupestres no Brasil) exploram a contextualização dos conteúdos apenas superficialmente, pois, não há uma articulação entre aspectos sociais (S), tecnológicos (T) e científicos (C) do tema, tendo sido enfatizados conhecimentos nas vertentes Sociedade e Ciências. Ao se observar a representação de cada uma dessas unidades (figuras 2 e 10, respectivamente), pode-se perceber que os conhecimentos que fazem parte da esfera da Sociedade (S) parecem expressar somente um contexto superficial, o que sugere a ideia de abordagens que apresentam conteúdos fugazes com o propósito de ensinar conteúdos (LUTFI, 1992). Deve ser ressaltada uma aparente contradição, pois a unidade 9 foi elaborada por um dos professores (P13) que apresentou, inicialmente, ideias coerentes do ponto de vista do ensino de Ciências CTS (ver Tabela 1).

Quadro 2. Conhecimentos das áreas CTS e enfoque atribuído às áreas nas unidades didáticas (segundo modelo de Aikenhead (1994)

\begin{tabular}{|c|c|c|c|c|c|c|c|c|c|}
\hline \multicolumn{8}{|c|}{ Conhecimentos das áreas CTS na unidade didática } \\
\hline Unidade & \multicolumn{2}{|c|}{$\begin{array}{c}\text { Informações presentes nos âmbitos CTS } \\
\text { segundo o Modelo de Aikenhead }\end{array}$} & \multicolumn{3}{|c|}{$\begin{array}{c}\text { Enfoque da unidade } \\
\text { (C) Ciencia, (T) Tecnologia, (S) } \\
\text { Sociedade e CTS }\end{array}$} \\
\hline 1 & $\mathrm{~S}$ & $\mathrm{~T}$ & $\mathrm{C}$ & $\mathrm{T}$ & $\mathrm{S}$ & $\mathrm{C}$ & $\mathrm{T}$ & $\mathrm{S}$ & CTS \\
\hline 2 & $\mathrm{X}$ & & $\mathrm{X}$ & & & $\mathrm{X}$ & & & \\
\hline 3 & $\mathrm{X}$ & $\mathrm{X}$ & $\mathrm{X}$ & $\mathrm{X}$ & $\mathrm{X}$ & & & & $\mathrm{X}$ \\
\hline 4 & $\mathrm{X}$ & $\mathrm{X}$ & $\mathrm{X}$ & & & $\mathrm{X}$ & & & \\
\hline 5 & $\mathrm{X}$ & & $\mathrm{X}$ & & $\mathrm{X}$ & $\mathrm{X}$ & & & \\
\hline 6 & $\mathrm{X}$ & $\mathrm{X}$ & $\mathrm{X}$ & $\mathrm{X}$ & & $\mathrm{X}$ & & & \\
\hline 7 & $\mathrm{X}$ & $\mathrm{X}$ & $\mathrm{X}$ & & $\mathrm{X}$ & $\mathrm{X}$ & & & \\
\hline 8 & $\mathrm{X}$ & $\mathrm{X}$ & $\mathrm{X}$ & $\mathrm{X}$ & $\mathrm{X}$ & & & & $\mathrm{X}$ \\
\hline 9 & $\mathrm{X}$ & $\mathrm{X}$ & $\mathrm{X}$ & & & $\mathrm{X}$ & & & \\
\hline & $\mathrm{X}$ & & $\mathrm{X}$ & & & & & & \\
\hline
\end{tabular}

Fonte: Elaborado pelos autores.

As unidades 3, 4 e 8 apresentaram um grau de incoerência menor, em relação ao modelo de Aikenhead (1994), do que as unidades 1 e 9; embora todas elas apresentem foco bem definidos no conceitual (C). As unidades 5 e 6 também apresentam foco conceitual, contudo, verifica-se uma distribuição de conhecimentos nas três áreas (CTS). A partir desta análise, pode-se inferir que os professores P11, que produziu a unidade 5, e P1, P4 e P9, que elaboraram a unidade 6, apresentaram certa evolução quanto aos entendimentos de contextualização. 
A unidade 2, elaborada pelo professor P8, e a 7, elaborada pelos professores P2 e P17, apresentam equilíbrio nas relações entre os conhecimentos referentes à Ciência, à Tecnologia e à Sociedade, como se verifica na tabela 3, o que pode indicar que os autores desses materiais abordaram mais as relações CTS do que uma ou outra dessas áreas. Nesta análise, é forte a evidência de que os professores em questão assimilaram as ideias de contextualização discutidas no decorrer da intervenção.

Comparando-se o foco do ensino contextualizado, apontado pelo professor (tabela 1), com as unidades produzidas, verifica-se que seis dos que apontaram a contextualização com vistas ao conceitual elaboraram unidades didáticas centradas, sobretudo, na ciência, mostrando uma coerência entre o manifestado e o planejado. Dos sete professores que apontaram o estudo de contexto como foco do ensino, apenas um participou da elaboração de uma unidade cujo enfoque foi por nós classificado como CTS. A outra unidade com ênfase CTS foi elaborada por um professor que apontou o ensino de conteúdos como foco do ensino contextualizado. Essa constatação pode ser importante quando se pensa em ações de formação continuada sobre esse assunto, devendo-se considerar que a manifestação de ideias mais elaboradas nem sempre se refletem na prática.

Uma vez verificadas essas tendências, procuramos, por meio de entrevistas semiestruturadas, investigar os fatores que levaram os professores a adotarem ideias distintas de contextualização na construção de suas unidades didáticas.

Procuramos entrevistar os professores mais emblemáticos, como P13, que elaborou a unidade 9, e os professores que produziram as unidades 2 e 7, contudo, após a recusa dos convites, realizaram-se as entrevistas com aqueles que aceitaram ser entrevistados voluntariamente. Assim, ao final do curso, foram realizadas seis entrevistas; entretanto, discutiremos neste trabalho as entrevistas de três professores que apresentaram entendimentos mais elaborados de contextualização e construíram unidades com entendimentos menos elaborados, e, ainda, de outro professor, que aparentemente não entendeu a contextualização na dimensão CTS.

As entrevistas foram divididas em dois blocos distintos. Inicialmente, procurou-se verificar como o professor entendia a contextualização no ensino de química; e, no segundo momento, procurou-se conhecer quais eram, para esses professores, os possíveis impedimentos para a realização de aulas com perspectivas mais elaboradas de contextualização.

No que tange aos entendimentos de contextualização CTS, um recorte do professor P9 aponta duas características marcantes detectadas nas entrevistas: a dificuldade em trabalhar com as ideias de contextualização mais elaboradas e a consideração de que o conteúdo químico é mais importante. Recorte de fala do professor P9.

\section{[...] eu acho que é a ordem das coisas, a problematização [...] acho que se eu inverter e trabalhasse melhor isso, problematizasse inicialmente, eu conseguiria chegar.}

Percebe-se que este professor apresenta certa compreensão das ideias de contextualização mais elaboradas, ao discutir a problematização.

Analisando a entrevista do segundo professor (P4), percebe-se que este, embora aparentemente tenha compreendido as ideias de contextualização, ainda vê o conceitual ditando os planejamentos do que ensinar. Neste sentido, o professor ressalta: 
[...] romper com a sequência de conteúdos, não é que é impossivel chegar, e que falta assim, um pouco de audácia mesmo, tentar fazer entendeu, acho que falta isso [...] porque eu achava que o conteúdo era importante, extremamente importante, que o exemplo já dava algum significado pro aluno e não dá [...]

Ele aponta que falta certa audácia para romper com a sequência habitual de conteúdos. Provavelmente, o professor compreendeu que, em materiais instrucionais com perspectivas de contextualização segundo orientações CTS, a sequência de conteúdos é pensada em função do contexto de estudo. Tal insegurança pode ser atribuída à formação inicial dos professores, pautada no ensino fragmentado e excessivamente disciplinar, sendo tais características, fatores que dificultam modificações na prática do professorado (MEMBIELA, 1995; SOLBES; VILCHES; GIL, 2002).

A manifestação citada a seguir fornece indícios de ampliação de entendimento do terceiro professor, P5, que, no caso, não elaborou unidade na mesma perspectiva de compreensão. Ele parece perceber a limitação de apenas ilustrar o conteúdo da química com exemplos. Os indícios ficam evidentes no trecho a seguir:

[...] não é fácil, porque você muda [...]. Tem de aprofundar um pouco mais, [...],
porque quando você vem com uma problematização os alunos automaticamente, opa
pera ai, vou perguntar isso, vou perguntar aquilo então, você tem que vir melhor
preparado, [...] vocêjjá vai percebendo o que os alunos pedem a vir te perguntar, assim
de repente, você pode ser pego de surpresa, não que você não saiba o conteúdo, mas a
maneira como você vai abranger eles, sendo que alguns pré-requisitos eles tem outros
não e a preparação mesmo, eu acho que é um pouco de insegurança [...]

O professor aponta a necessidade de se ter conhecimentos mais amplos para elaborar aulas contextualizadas, e demonstra certa insegurança para realizá-las. Talvez este seja um dos maiores fatores que o impediram de desenvolver uma unidade com ideias mais elaboradas de contextualização.

A entrevista do quarto professor (P3) pode revelar um entendimento de contextualização pouco elaborado, baseado na introdução de curiosidades ou interesses imediatos que os alunos têm e trazem para as aulas de química (CAJAS, 2001; LUTFI, 1992). A seguinte manifestação deste professor contribui para reforçar essa ideia, quanto à questão da sequência tradicional do conteúdo programático:

[...] sem problemas, volto pra ele, sempre procurando encaixar aquilo que o aluno me trouxe, a curiosidade dele, isso é trabalhar cotidiano do aluno, você pegar a partir da curiosidade do aluno [...]

Sobre a elaboração e implementação das unidades didáticas, alguns aspectos chamaram a atenção. Começamos por destacar a manifestação de um dos entrevistados, P16. Ele chama a atenção para o tempo que careceria para adotar tal postura: 
[...] eu tenho que sentar e fazer isso fora do meu horário de aula, eu tenho que sentar e arrumar um tempo pra mim, na minha casa, separar a minha vida pessoal da profissional, sentar ali esse aqui é meu projeto, sentar e fazer, falta isso [...]

Recaímos, aqui, no fator carga horária de trabalho dedicada ao preparo das aulas, ou seja, o professor argumenta que, para dar uma aula contextualizada, é necessário se preparar, estudar, e que ele não tem tempo para isso.

Parte dos professores apontou, como um dos impedimentos para elaboração, e posterior aplicação de uma unidade didática, o número elevado de aulas ministradas por período; ou seja, para que desenvolver um material tão elaborado sendo que não seria aplicado em sua plenitude? Um recorte de uma das entrevistas, do professor P6, aponta:

[...] quando você tem 200 alunos e você conhece um por um, é mais fácil isso, então, a questão de ter duas aulas semanais implica que o professor faça o que? Pegue um número de aulas, um número de salas muito grande. Eu tenho por volta de 700 alunos, é difícil você trabalhar com 700 alunos e estar estabelecendo essa relação afetiva com eles, conhecer cada um, seus problemas, as dificuldades é isso que dificulta, en acredito que seja isso [...]

Gasparini, Barreto e Assunção (2005) apontam que, embora o sucesso escolar também dependa do professor, a gestão escolar não fornece condições para a realização de tarefas mais complexas. É fato que os professores, sobretudo dos grandes centros urbanos, encontram condições adversas no trabalho, como, por exemplo, salas superlotadas de alunos e, ainda, têm de se sujeitar a dar uma quantidade excessiva de aulas semanais, para ter melhor remuneração. Assim, eles se veem obrigados a buscar, por seus próprios meios, formas de requalificação que acabam, ao final, não sendo postas em prática nas aulas.

Outro professor, P3, sobre a possível implementação, argumenta que:

[...] eu tenho duas aulinhas por semana, é assim, tem salas que é um dia da semana e só são aquelas duas se você tem um feriado a gente atrasa um pouco o conteúdo, se bem que a gente não pode ficar preso ao plano de ensino, mas poderia ser melhor, o número de aulas é bastante pouco [...]

O professor levanta uma questão que envolve políticas públicas, talvez por entender que duas aulas semanais de química não são o bastante para desenvolver aulas contextualizadas. Essa perspectiva do professor parece revelar a fragilidade com que os temas de interesse dos alunos são tratados em sala.

Embora todos estes fatores formem uma complexa teia, dois deles podem ser destacados como os mais desvelados nas entrevistas: um que diz respeito à formação tradicional do professor, fundamentada no conhecimento específico da química (MARTINS, 2002) e na abordagem pautada na sequência habitual do livro didático (MALDANER, 2000); e outro de natureza prático-profissional, que diz respeito ao preparo pessoal do professor e de suas aulas, o que exigiria maior demanda de trabalho, de maneira a resguardar o papel de professor que tudo conhece. 


\section{Conclusão e considerações finais}

A análise das unidades didáticas produzidas mostrou que um pequeno número de professores pode ter ampliado seu entendimento da temática CTS, uma vez que estes construíram materiais em que se puderam reconhecer interações ciência-sociedade; de acordo com o modelo proposto neste trabalho. Contudo, na elaboração das unidades, estas ideias não foram levadas em consideração. Mas, mesmo frente a esses tímidos avanços, a construção de materiais didáticos (MAZZEU, 1998; TENREIRO-VIEIRA; VIEIRA, 2005) se mostrou uma alternativa eficaz na formação dos professores de química. A autoria de seu material instrucional pode conferir, ao professor, maior autonomia pedagógica, talvez até maior criticidade em relação aos livros didáticos, além de contribuir para o aumento da autoestima.

Por meio das entrevistas, foram identificados alguns fatores que permitiram elucidar as dificuldades dos professores na construção dos materiais instrucionais. Um desses fatores diz respeito ao número elevado de aulas que os professores ministram, em, pelo menos, dois períodos do dia, acarretando um número exorbitante de aulas ao final da semana. Também, os professores apresentam dificuldades em lidar com a elaboração e aplicação de materiais didáticos CTS, numa perspectiva de aulas dialogadas, talvez por dois motivos: formação dentro de um paradigma tradicional e fragmentado, que caracteriza uma relação vertical professor-aluno, e o número elevado de alunos por sala. Nestas condições, é esperado que uma aula dialogada fosse difícil de acontecer em sua plenitude.

Essa pesquisa aponta a necessidade de outros estudos que tragam mais contribuições para se entenderem os mecanismos de barreiras epistemológicas, afetivas e cognitivas que controlam escolhas e decisões dos professores no processo educativo, e, de certo, os impedem de colocar em prática a potencialidade de um ensino socialmente contextualizado.

\section{Referências}

ACEVEDO, J. A. Cambiando la práctica docente en la enseñanza de las ciencias a través de CTS. Boletín de Área de Cooperación Científica de la OEI, Madrid, n. 15, jun. 2001. Disponível em: < http://www.campus-oei.org/salactsi/acevedo2.htm>. Acesso em: 04 abr. 2006.

AIKENHEAD, G. S. The social contract of science: implications for teaching science In: SOLOMON, J.; AIKENHEAD, G. S. (Org.). STS education-international perspectives on reform. New York: Teachers College Press, 1994. p. 11-20.

ANDRÉ, M. E. A.; LÜDKE, M. Pesquisa em educação. São Paulo: EPU, 1986. (Temas básicos de educação e ensino). 
AULER, D. Alfabetização cientifico-tecnológica. Ensaio: pesquisa em educação em ciências, Belo Horizonte, v. 5, n. 1, p. 1-16, 2003. Disponível em: <www.fae.ufmg.br/ensaio>. Acesso em: 02 jan. 2010.

- Alfabetização científico-tecnológica para quê? Ensaio: pesquisa em educação em ciências, Belo Horizonte, v. 3, n. 2, p. 12-15, 2001.

AULER, D.; FENALTI, V. S.; DALMOLIN, A. M. T. Abordagem temática: temas em Freire e no enfoque CTS. In: ENCONTRO NACIONAL DE PESQUISA EM ENSINO DE CIÊNCIAS, 6., 2007, Florianópolis. Anais... Florianópolis: ABRAPEC, 2007. Disponível em: <http://www.fae.ufmg.br/abrapec/cdrom/entrar.htmlhttp://www.saum.uvigo.es/reec/ volumenes/ volumen2/>. Acesso em: 23 jun. 2008.

BOGDAN, R.; BIKLEN, S. K. Investigação qualitativa em educação: uma introdução à teoria e aos métodos. Porto: Porto, 1994.

BRASIL. Ministério da Educação e Cultura. Parâmetros curriculares nacionais do ensino médio. Brasília: MEC/SEMTEC, 1999.

CAJAS, F. Alfabetización científica y tecnológica: la transposición didáctica del conocimiento tecnológico. Enseñanza de las Ciencias, Barcelona, v. 19, n. 2, p. 243-254, 2001.

CEREZO, J. A. L. Los estúdios de ciência, tecnologia y sociedad. Revista Iberoamericana de Educación, Madrid, v. 20, 1999. Disponível em: <http://www.oei.es/salactsi/ cerezorie20.htm>. Acesso em: 11 jun. 2007.

DELIZOICOV, D.; ANGOTTI, J. A. Física: formação geral. São Paulo: Cortez, 1991. (Coleção Magistério).

GASPARINI, S. M.; BARRETO, S. M.; ASSUNÇÃO, A. A. O professor, as condições de trabalho e os efeitos sobre sua saúde. Educação e Pesquisa, São Paulo, v. 31, n. 2, p. 189-199, 2005.

LUTFI, M. Os ferrados e cromados: produção social e apropriação privada do conhecimento químico. Ijuí: Ed. UNIJUÍ, 1992.

MALDANER, O. L. Formação inicial e continuada de professores de química. 3. ed. Ijuí: Unijuí, 2000. (Coleção Educação em química).

MARCONDES, M. E. R. et al. Oficinas temáticas no ensino público visando a formação continuada de professores. São Paulo: Imprensa Oficial do Estado de São Paulo, 2007.

MARTINS, I. P. Problemas e perspectivas sobre a integração CTS no sistema educativo português. Revista Electrónica de Enseñanza de las Ciencias, Vigo, v. 1, n. 1, p. 28-39, 2002. Disponível em: <http://saum.uvigo.es/reec/volumenes/volumen1/Numero1/Art2. pdf>. Acesso em: 22 abr. 2007. 
MAZZEU, F. J. C. Uma proposta metodológica para a formação continuada de professores na perspectiva histórico-social. Cadernos Cedes, Campinas, v. 19, n. 44, p. 59-72, 1998. Disponível em: <http://www.scielo.br/scielo.php?script=sci_arttext\&pid=S010132621998000100006\&lng=pt\&nrm=iso >. Acesso em: 23 fev. 2007.

MEMBIELA, P. CTS en la enseñanza-aprendizaje de las ciencias experimentales. Alambique: didáctica de las ciencias experimentales, Barcelona, n. 3, p. 7-11, 1995.

MORTIMER, E. F.; MACHADO, A. H. Química para o ensino médio: fundamentos, pressupostos e o fazer cotidiano. In: ZANON, L. B.; MALDANER, O. A. (Org.).

Fundamentos e propostas de ensino de química para a educação básica no Brasil. Ijuí: Ed. Unijuí, 2007. p. 21-41.

SANTOS, W. L. P. Uma análise de pressupostos teóricos da abordagem C-T-S (ciênciatecnologia-sociedade) no contexto da educação brasileira. Ensaio: pesquisa em educação em ciências, Belo Horizonte, v. 2, n. 2, p. 1-23, 2002. Disponível em: <http://www.portal.fae. ufmg.br/seer/index.php/ensaio/article/view/21/52>. Acesso em: 20 jan. 2010.

SOLBES, J.; VILCHES, A.; GIL, D. Formación del profesorado desde el enfoque CTS. In: MEMBIELA, P. (Org.). Enseñanza de las ciencias desde la perspectiva cienciatecnología-sociedad: formación científica para la ciudadanía. Madrid: Narcea, 2002. p. $163-178$.

TENREIRO-VIEIRA, C.; VIEIRA, R. M. Construção de práticas didático-pedagógicas com orientação CTS: impacto de um programa de formação continuada de professores de ciências do ensino básico. Ciência \& Educação, Bauru, v. 11, n. 2, p. 191-211, 2005. 